\title{
Oat $\beta$-glucan: physico-chemical characteristics in relation to its blood-glucose and cholesterol-lowering properties
}

\author{
Qi Wang ${ }^{1 *}$ and Peter R. Ellis ${ }^{2}$ \\ ${ }^{1}$ Guelph Food Research Center, Agriculture and Agri-Food Canada, 93 Stone Road West, Guelph, ON, Canada \\ ${ }^{2}$ Biopolymers Group, Diabetes and Nutritional Sciences Division, School of Medicine, King's College London, \\ Franklin-Wilkins Building, 150 Stamford Street, London, UK
}

(Submitted 3 October 2013 - Final revision received 28 May 2014 - Accepted 17 June 2014)

\begin{abstract}
The water-soluble, mixed-linkage $\beta$-glucan, a form of soluble dietary fibre, is considered the main biologically active component responsible for the capacity of many oat products to lower postprandial glycaemia and fasting plasma cholesterol in human subjects. The present review discusses the physical and chemical properties of oat $\beta$-glucan that are considered important predictors of these beneficial metabolic effects. In vitro modelling and animal and human studies have provided compelling evidence showing that the ability of oat $\beta$-glucan to increase the viscosity of digesta in the gastrointestinal tract (GIT) is a primary determinant of its blood-glucose and cholesterol-lowering properties. Therefore, the chemical structure, molecular weight (MW), the rate and extent of dissolution and solution rheology of oat $\beta$-glucan are key factors in determining the physiological function of oat-containing foods. The structure and properties of oat $\beta$-glucan vary between species and varieties of oats, and are also affected by the growing and storage conditions and processing of oat grain. In addition, the extraction and analysis methods may also contribute to the variations in the structure, MW, hydration and solution rheology of $\beta$-glucan obtained from different laboratories. Recent work has demonstrated that $\beta$-glucan solubility in foods depends on the source of the material and processing conditions; solubility may also be subject to changes during food preparation and storage (such as freezing). In conclusion, both the amount and MW of $\beta$-glucan that are solubilised in the GIT need to be considered when assessing the blood-glucose and cholesterol-lowering properties of oat-containing foods.
\end{abstract}

Key words: Oat $\beta$-glucan: Soluble fibre: Solubility: Molecular weight: Viscosity: Plasma cholesterol: Blood glucose

Many in vitro animal and human studies have shown that water-soluble $\beta$-glucan is one of the main bioactive components responsible for a number of the putative health benefits attributed to oat products, as highlighted in the articles in this Supplement of the British Journal of Nutrition. The biological behaviour of this polysaccharide is of particular importance in relation to the well-documented effects of oat bran in reducing postprandial glycaemia, insulinaemia and fasting concentrations of the plasma cholesterol (usually the LDL-cholesterol fraction).

The basic chemical structure of oat $\beta$-glucan was elucidated as early as the $1960 \mathrm{~s}^{(1)}$ and many aspects of its physiochemical properties have also been known for some time ${ }^{(2)}$. However, the critical role of the physico-chemical properties of oat $\beta$-glucan, notably solution rheology, in determining the physiological effects of oat-containing foods has been more difficult to establish, although understanding of this has improved significantly in recent years. As with other types of water-soluble dietary fibre, such as guar gum (a galactomannan-rich leguminous seed flour), oat $\beta$-glucan may confer its physiological influence by the combination of a number of mechanisms. The mechanisms involved in modifying digestion kinetics include, but are not limited to ${ }^{(3-6)}$, increasing digesta viscosity in the lumen of the gastrointestinal tract (GIT), interacting with starch and other nutrients, interfering with the activity of gut enzymes (e.g. pancreatic $\alpha$-amylase) and increasing bile salt excretion. For instance, the effects of oat $\beta$-glucan and similar forms of fibre on postprandial glycaemia are strongly related to their capacity to reduce the rate of digestion of macronutrients such as $\operatorname{starch}^{(3,7)}$.

The aim of the present paper is to review the physical and chemical properties of oat $\beta$-glucan that have been suggested as potentially influencing gut function and metabolism, a topic covered by other papers in this special issue. The present paper provides some mechanistic insight of the nutritional properties of oat products, with a specific focus on the capacity of oat $\beta$-glucan to lower blood-glucose and cholesterol concentrations in human subjects.

Abbreviations: GIT, gastrointestinal tract; MW, molecular weight.

*Corresponding author: Q. Wang, fax +1 226217 8181, email qi.wang@agr.gc.ca 


\section{Molecular structure and conformation}

\section{Chemical structure}

Oat $\beta$-glucan is a linear polymer of D-glucose bonded by $\beta-(1 \rightarrow 4)$ and $\beta-(1 \rightarrow 3)$ glucosidic linkages. About $90 \%$ of the glucose units are arranged in blocks of $\beta$ - $(1 \rightarrow 3)$-linked cellotriosyl and cellotetraosyl units, with the rest being the longer cellulosic segments (Fig. 1). The ratio of trisaccharidestetrasaccharides in oat $\beta$-glucan is typically $2: 1$, which is distinctively different from that found in barley $(3: 1)$ and wheat $(4: 1) \beta$-glucans ${ }^{(8,9)}$. This structural variation leads to differences in some of the physical properties of these $\beta$-glucans, which will be discussed in the following sections. A small variation in the trisaccharide-tetrasaccharide ratio has been reported for oat $\beta$-glucan, which may arise from several factors including differences between species ${ }^{(10)}$, growing conditions, and extraction and analytical methods. A number of reports have suggested the presence of amino-acid residues ${ }^{(11,12)}$ and inner C-6 carbon-bound phosphomonoesters ${ }^{(13)}$ in the oat $\beta$-glucan molecule. However, these additional structural features have not always been observed.

\section{Molecular weight and conformation}

The molecular weight (MW) and conformation of oat $\beta$-glucan are important because they can largely determine many other physical properties, including the solubility, solution viscosity and viscoelasticity and gelation properties. For instance, high MW oat $\beta$-glucan does not form a gel, but gels can be produced from samples with reduced MW under certain conditions $^{(14,15)}$. All the studies so far have indicated that oat and other cereal $\beta$-glucans adopt overall an extended random coil conformation in aqueous solution ${ }^{(16-18)}$. Oat $\beta$-glucan, like all other natural polysaccharides, has a MW distribution that is polydisperse. This means that, instead of one unique value (as in proteins), a wide MW distribution exists in each polymer sample. Therefore, depending on the method used for the measurement, various MW averages are obtained to describe a polymeric material. The weight-average MW and number-average $\mathrm{MW}\left(M_{\mathrm{w}}\right.$ and $\left.M_{\mathrm{n}}\right)$ are the most frequently encountered values for $\beta$-glucans, which are often measured, for example, by static light-scattering and osmotic pressure measurements, respectively ${ }^{(12,19,20)}$. High-performance size exclusion chromatography has been extensively used in recent years for characterisation of $\beta$-glucan. When connected with multi-detectors (using reflective index, light scattering and viscometry), the high-performance size exclusion chromatography method can provide a range of molecular parameters in addition to the MW distribution and average $\mathrm{MW}^{(21)}$. The method of specific dye binding of calcofluor to cereal $\beta$-glucans offers a unique way of determining the MW of $\beta$-glucan by high-performance size exclusion chromatography. The post-column detection of calcofluor binding to

$$
\ldots{ }^{4} \mathrm{G}_{1}{ }^{3} \mathrm{G}_{1}\left[{ }^{4} \mathrm{G}_{1}{ }^{4} \mathrm{G}_{1}{ }^{3} \mathrm{G}_{1}\right]_{\mathrm{m}}\left[{ }^{4} \mathrm{G}_{1}{ }^{4} \mathrm{G}_{1}{ }^{4} \mathrm{G}_{1}{ }^{3} \mathrm{G}_{1}\right]_{\mathrm{n}}{ }^{4} \mathrm{G}_{1}{ }^{4} \mathrm{G}_{1}{ }^{4} \mathrm{G}_{1}{ }^{4} \mathrm{G}_{1} \ldots
$$

Fig. 1. Chemical structure of oat $\beta$-glucan. $G$ represents a glucose unit and the numbers indicate the linkage sites; the ratio of $m / n$ is approximately 2 . $\beta$-glucan makes it possible to measure $\beta$-glucan in the presence of other polysaccharides that do not bind this fluorescent $\operatorname{stain}^{(22,23)}$. This is especially useful in making comparisons between different food products and extracts containing $\beta$-glucan, because purification of $\beta$-glucan is not necessary before the measurement.

\section{Factors that affect the molecular weight}

The MW of $\beta$-glucan in common oat grain (Avena sativa L.), which is the main commercial species, is influenced by the variety and growing conditions ${ }^{(24,25)}$. It has not been possible to directly measure the MW of $\beta$-glucans in the cellwall matrix of oat grain. The MW of $\beta$-glucan in groats or flour is subject to changes caused by endogenous hydrolytic enzymes, and various processing and storage factors. Because endo- $\beta$-glucanases are present in oat seeds ${ }^{(26)}$, inactivation of these enzymes (such as by IR heating, steaming or boiling in aqueous ethanol) is considered essential to obtain high MW $\beta$-glucan extracts from the oat-grain cell walls ${ }^{(27,28)}$. The reported MW of $\beta$-glucan is also therefore subject to significant variations, as a result of differences in the conditions used for extraction and purification of the polysaccharide. The MW obtained for purified oat $\beta$-glucans through a well-designed process to minimise molecular depolymerisation is in the range of $2 \times 10^{6}$ to $3 \times 10^{6} \mathrm{Da}$. It is known that the MW of $\beta$-glucan can be decreased as a result of food preparation such as bread-making ${ }^{(29)}$, baking of muffins or cookies ${ }^{(30,31)}$, and extensive extrusion ${ }^{(32)}$. Aman et al. $^{(33)}$ reported that the MW of $\beta$-glucan was preserved in rolled oats, oat bran and different types of oat-bran concentrate, porridge and pancakes, whereas the degradation of $\beta$-glucan was observed in bread, pasteurised apple juice, pasta and teacake (see Decker et $a l^{\left({ }^{(3)}\right.}$ in this Supplement for more examples).

\section{Solubility and extractability}

\section{Content and location in oat grain}

The $\beta$-glucan contents in oat groats vary considerably with cultivars and growing conditions. It has been shown that a 2 - to 3 -fold variation in the $\beta$-glucan content exists among oat cultivars ${ }^{(10,25,35)}$. A number of surveys from different parts of the world revealed that the $\beta$-glucan contents were in the range of $1.8-5.5 \%$ of the total dry weight of the oat groat, and frequently in the range of $4 \cdot 5-5 \cdot 5 \%(10,36,37)$. Higher $\beta$-glucan contents of up to $7 \%$ have also been reported for some oat varieties ${ }^{(34)}$.

Oat $\beta$-glucan is primarily located in the cell walls of the starchy endosperm (Fig. 2). The endosperm cell walls of oats ${ }^{(38)}$ have a layered structure. In this layered structure, there is a relatively thin outer layer, consisting of mainly water-insoluble polysaccharides such as cellulose, glucomannan and arabinoxylan, and a thick inner layer of water-soluble polysaccharide, most of which consist of the mixed linkage $\beta$-glucan plus a small amount of soluble arabinoxylan. The cell wall of the subaleurone layer is usually much thicker than that of the inner endosperm $^{(39)}$ and is rich in $\beta$-glucan. A relatively thin layer of 


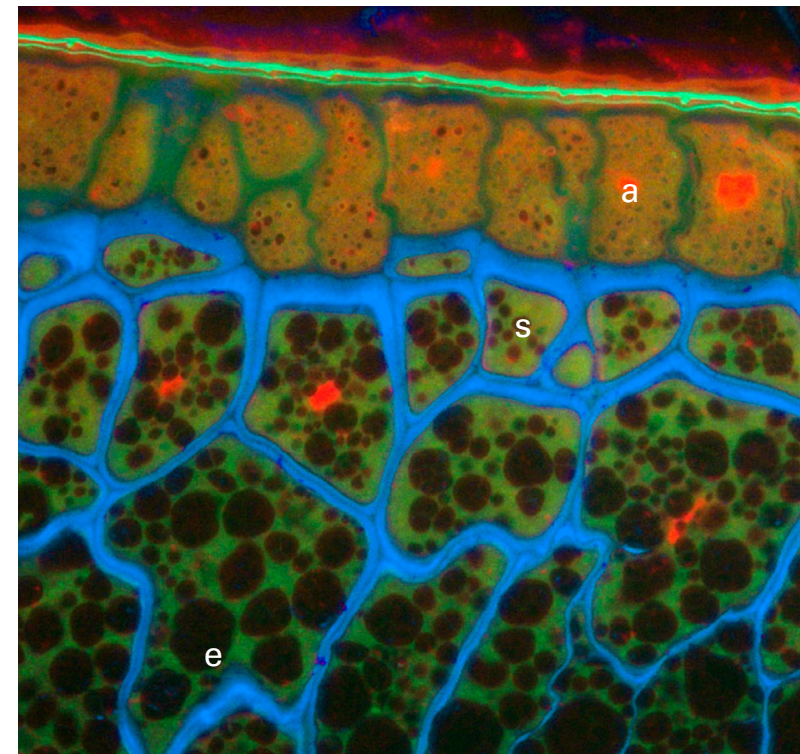

Fig. 2. $\beta$-Glucan in the cell wall of oat stained with calcofluor. a, aleurone; $\mathrm{s}$, subaleurone; e, endosperm. (Courtesy of S. Shea Miller, Agriculture and Agri-Food Canada.)

$\beta$-glucan is also found in the inner layer of the aleurone cell walls. This inner layer is surrounded by a thick insoluble outer layer, which in turn makes the $\beta$-glucan less readily soluble compared with the endosperm $\beta$-glucan ${ }^{(38,39)}$.

\section{Solubility and its determination}

In the literature, the term 'solubility' for a polysaccharide does not represent the true thermodynamic equilibrium solubility. Rather, it is used to refer to the property of a polysaccharide in a solid form or contained in a solid food matrix to disperse in a liquid medium (often water) and form a homogeneous dispersion under specified conditions. It is sometimes used interchangeably with the word 'extractability' of the polysaccharides. Solubility is usually expressed by the percentage of the dissolved fraction relative to the total amount of the polysaccharide in the original solid matrix under specific conditions (such as temperature).

The solubility of $\beta$-glucan in water has been tested recently under different conditions of processing and laboratory measurements ${ }^{(40)}$. The choice of the method depends on the objective of the investigation. Clearly, it is only meaningful to compare the solubility of different $\beta$-glucans, and indeed other polysaccharide preparations, under the same conditions. In order to establish reliable methods for the preparation of $\beta$-glucan concentrates with maximum yields and minimal depolymerisation, several studies have been carried out to compare extractability of $\beta$-glucan under various conditions. Different extraction schemes have been developed based on these studies for laboratory or commercial production of $\beta$-glucan, and the methods have been reviewed previously $^{(41,42)}$. The extractability of $\beta$-glucan was found to be strongly dependent on many factors, such as temperature, $\mathrm{pH}$ and the presence of digestive enzymes. When the health benefits of $\beta$-glucan as a soluble fibre are of primary interest, the solubility properties of $\beta$-glucan under conditions close to the gut environment are highly relevant. Because animal and human trials are expensive and time-consuming, having an in vitro method as a pre-screening tool to evaluate the properties of $\beta$-glucan in oat products is very useful.

There are two main types of in vitro methods used to evaluate the solubility of $\beta$-glucan in foods. One of these is designed to simulate physiological conditions of digestion in the upper $\operatorname{GIT}^{(30,43)}$ of human subjects. For a typical example of such a procedure, see the online supplementary materials. This method involves incubating test foods with a series of digestive enzymes at human body temperature $\left(37^{\circ} \mathrm{C}\right)$ and appropriate $\mathrm{pH}$ levels for defined periods to simulate the acidic and neutral conditions in the stomach and small intestine, respectively. The solubilised $\beta$-glucan in the supernatant can then be quantitatively measured by the method of Jørgensen \& Aastrup $^{(44)}$, and the total $\beta$-glucan content in the same sample can be measured by the method of McCleary \& Glennie-Holmes ${ }^{(45)}$. A similar procedure has been developed by directly measuring the viscosity developed during the simulated digestion process. This allows the contribution of solubility and MW of $\beta$-glucan to the viscosity to be accounted for simultaneously ${ }^{(46)}$. Another procedure, which adapts essentially the method of Asp et al. ${ }^{(47)}$, was developed initially for the isolation of water-soluble $\mathrm{NSP}^{(40)}$. This method involves a de-starching process during which the samples are treated at boiling temperature to allow starch gelatinisation. The starch and protein are then hydrolysed by various enzymes, and $\beta$-glucan is precipitated from the supernatants by alcohols. A similar approach to this is the use of hotwater extraction at $100^{\circ} \mathrm{C}$ with only a heat-stable $\alpha$-amylase and $0 \cdot 28 \mathrm{mg} / \mathrm{ml} \mathrm{CaCl}_{2}$ added $^{(23,25,33)}$. Few direct comparisons have been made among the results from these methods. Because it is known that increasing extraction temperature increases the solubility of the polymer ${ }^{(40)}$, the amount of solubilised $\beta$-glucan is likely to be lower using in vitro physiological extraction than that obtained using the hot-water extraction method ${ }^{(30)}$. Further work is required, therefore, to investigate the precise relationship between in vitro measurements of $\beta$-glucan solubility and polysaccharide dissolution in vivo.

\section{Factors that influence solubility}

Sources. As mentioned earlier, most $\beta$-glucan in the oat groat is located in the inner layer of the cell wall that is enclosed by an insoluble cellulosic and hemicellulosic outer layer. It is generally less water soluble than extracted $\beta$-glucan material. Because the cell walls in the inner endosperm are thinner than in the aleurone and subaleurone layers, it appears that $\beta$-glucan in the milled whole groat is more easily extracted than that in oat bran ${ }^{(30,38)}$. For example, Beer et al. ${ }^{(30)}$ has found that the proportion of soluble $\beta$-glucan extracted from oat brans and rolled oats, by hot-water extraction in conjunction with a heat-stable $\alpha$-amylase treatment, was 30-65 and $70 \%$, respectively (Table 1 ). Under physiological conditions, the percentage of extractable $\beta$-glucan was also noticeably higher in rolled oats than in bran samples. 
Table 1. The $\beta$-glucan content and the percentage and molecular weight of extracted $\beta$-glucan from oat bran and rolled oats using hot water $\left(90^{\circ} \mathrm{C}\right.$ for $2 \mathrm{~h}$ with Termamyl) or physiological in vitro digestion method ${ }^{(30)}$

\begin{tabular}{|c|c|c|c|c|c|}
\hline \multirow[b]{2}{*}{ Sample } & \multirow[b]{2}{*}{$\beta$-Glucan $(\mathrm{g} / 100 \mathrm{~g})$} & \multicolumn{2}{|c|}{$\begin{array}{l}\beta-\text {-Glucan extracted } \\
(\% \text { of total })\end{array}$} & \multicolumn{2}{|c|}{$\begin{array}{l}\text { Molecular weight } \\
\quad\left(\times 10^{-3} \mathrm{Da}\right)\end{array}$} \\
\hline & & Hot water & Physiological & Hot water & Physiological \\
\hline Bran A & $13 \cdot 4$ & $51 \cdot 3$ & $12 \cdot 9$ & 1400 & 1100 \\
\hline Bran B & 8.9 & $56 \cdot 7$ & $25 \cdot 1$ & 1600 & 1800 \\
\hline Bran C & $7 \cdot 6$ & $64 \cdot 1$ & $28 \cdot 7$ & 1800 & 1900 \\
\hline Bran $C^{*}$ & ND & $30 \cdot 2$ & ND & 1800 & \\
\hline Rolled oats* & $4 \cdot 2$ & 69.5 & 33.4 & 1500 & 1500 \\
\hline
\end{tabular}

ND, not determined.

* Samples cooked before extraction.

Processing and food preparation. The solubility of $\beta$-glucan from oat bran varies largely because of different processing conditions in addition to varietal differences ${ }^{(48)}$. Using an in vitro digestion model to simulate human digestion, Beer et al. ${ }^{(30)}$ found that only $12-33 \%$ of total $\beta$-glucan in bran and rolled oats was solubilised, whereas Tosh et al. $^{(32)}$ reported a slightly higher solubility value of $39 \%$ in a commercial oat bran. When the oat bran was incorporated into an extruded cereal, the solubility of $\beta$-glucan increased markedly from 39 to $67 \%$ in breakfast cereals prepared under mild extrusion conditions. Further increases in the extrusion temperature and mechanical disruption resulted in a complete solubilisation of $\beta$-glucan, although the process was accompanied by a $>10$-fold decrease in MW. Microscopy observations clearly showed that extrusion disrupted the cellwall structure from which $\beta$-glucan labelled by calcofluor was released and dispersed into the food matrix (Fig. 3). Zhang et $a l^{(49)}$ also reported that extrusion improved the solubility of $\beta$-glucan in oat bran. Johansson et al. ${ }^{(40)}$ have shown that the baking of wheat bread with oat bran and subsequent drying of the bread decrease the amount of $\beta$-glucan solubilised, whereas the cooking of oat flakes as porridge increases it. Also, fermentation of oat bran by rye sourdough was shown to increase the solubility of oat $\beta$-glucan ${ }^{(40,50)}$.

The presence of endogenous enzymes, mainly $\beta$-glucanase, can have both detrimental and beneficial effects, the former being a depolymerisation of $\beta$-glucan and the latter being an increase in polymer solubility ${ }^{(51)}$. In a study by Tosh et $a{ }^{(52)}$, $\beta$-glucanase at different concentrations was added to the wheat dough containing oat bran to produce muffins containing different MW $\beta$-glucans. A decrease in MW of $\beta$-glucan from 2200000 to $400000 \mathrm{Da}$ led to an increase in the solubility of $\beta$-glucan in oat-bran muffins from 44 to $57 \%$. This phenomenon is in agreement with dissolution studies showing that the hydrolysis of a similar water-soluble polysaccharide, such as guar galactomannan, significantly increased solubilisation of the polymer ${ }^{(53)}$. However, when the MW was reduced further to $120000 \mathrm{Da}$, the solubility of $\beta$-glucan decreased to as low as $26 \%$. The authors suggested that the subsequent diminution of $\beta$-glucan solubility at very low MW (120000 Da) was due to a stronger self-association of the depolymerised $\beta$-glucan, thus leading to the formation of insoluble aggregates. It is also worth speculating that the interaction of $\beta$-glucan with other food components, especially proteins via the Maillard reaction, might have contributed to the low solubility. Lower MW polysaccharides seem to possess an increased reactivity towards proteins ${ }^{(54)}$ and other components found in foods ${ }^{(15,55)}$

Storage. Storage conditions have been shown to alter the solubility of $\beta$-glucan in oat-containing products. Beer et $a l .{ }^{(30)}$ noticed that frozen storage reduced the amount of extractable (soluble) $\beta$-glucan in oat muffins and the degree of reduction depended on the other ingredients in the formulation. After 8 weeks of storage, there was up to a $50 \%$ decrease in the extractable $\beta$-glucan in the muffins. A more recent study demonstrated that taking fresh muffins through a number of freeze-thaw cycles, each consisting of $14 \mathrm{~h}$ at $-18^{\circ} \mathrm{C}$ and $10 \mathrm{~h}$ at room temperature, progressively reduced
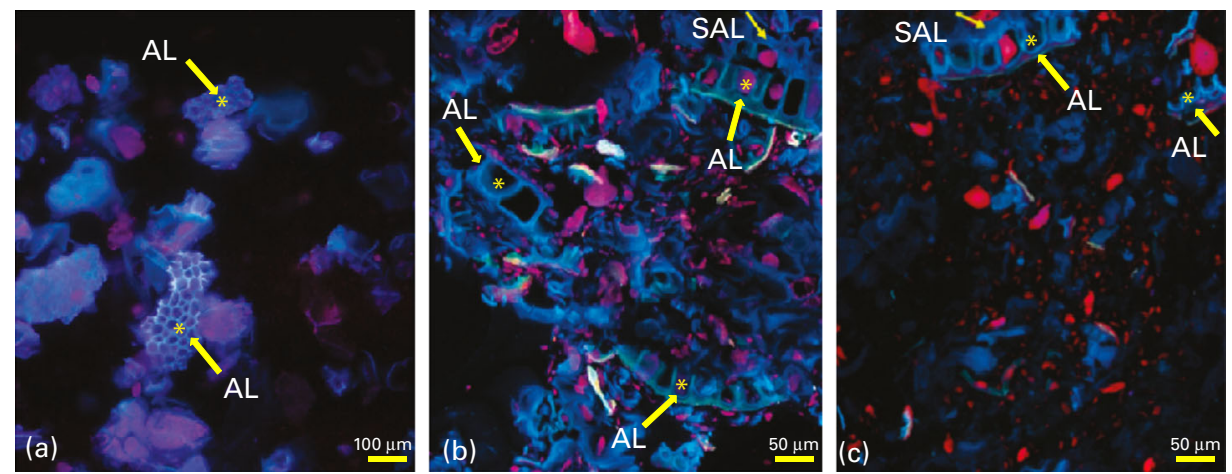

Fig. 3. Cryosections of test cereals, stained with calcofluor and mounted in acid fuchsin, showing that extrusion disrupted the cell wall structure, during which $\beta$-glucan (blue stain) was released and dispersed into the food matrix. (a) Premix (control); (b) after moderate extrusion and (c) after extensive extrusion. $\mathrm{AL}$, aleurone cells; SAL, subaleurone cell walls. (Adapted from Tosh et al. ${ }^{(32)}$, with permission). 
$\beta$-glucan solubility in the muffins. After four cycles of freezethaw treatment, the extractable $\beta$-glucan was reduced by over $50 \%{ }^{(56)}$. The authors ascribed the loss of solubility of $\beta$-glucan during frozen storage to the reorganisation of $\beta$-glucan chains due to intermolecular interactions (mostly stabilised by hydrogen bonding), which are likely to lead to increased ordered structure $^{(14)}$

Isolation and purification. The extent and rate of dissolution of isolated and purified $\beta$-glucan powders has not been well investigated, in contrast to materials such as galactomannan-rich guar-gum powders ${ }^{(53,57,58)}$. Panahi et al. ${ }^{(59)}$ showed that an oat $\beta$-glucan concentrate $(60 \%$ of $\beta$-glucan on dry weight basis) prepared by an alcohol-based enzymic technique had better solubility and higher MW than the product produced by a conventional aqueous extraction process. It has long been known that the solubility of isolated $\beta$-glucan is influenced by the drying method. Freeze-dried oat and wheat $\beta$-glucans are sometimes difficult to dissolve in water $^{(9)}$; the replacement of water molecules with isopropanol before drying (the so-called solvent exchange process) is critical to ensure good solubility of $\beta$-glucan isolates. The effect of MW on the solubility of $\beta$-glucan isolates therefore also depends on the way in which the isolate is prepared. In general, the ease of solubilisation of a polymer decreases as MW increases. This behaviour was demonstrated clearly with guar galactomannan powders where an inverse relationship between the dissolution rate and MW was observed ${ }^{(53)}$. Recently, Kim \& White ${ }^{(7)}$ reported that the solubility of a $\beta$-glucan isolate decreased with an increase in MW in a starch suspension after in vitro digestion. This is not always the case with oat $\beta$-glucan isolates, however. When the solvent exchange stage before drying is omitted, low-MW $\beta$-glucan molecules can potentially form stronger polymer-polymer interactions than the high-MW molecules do, which may then lead to a low solubility.

\section{Rheological properties in aqueous medium}

\section{Viscoelastic properties of $\beta$-glucan solution}

A freshly prepared and fully hydrated oat $\beta$-glucan solution behaves as a typical neutral random-coil polysaccharide solution. The viscosity of a polysaccharide solution depends on the structure, MW and polymer concentration, as well as conditions of measurement, such as shear rate and temperature. The shear rate dependence of viscosity for oat $\beta$-glucan has been extensively studied ${ }^{(2,60)}$. In terms of conditions in the GIT, shear rate is related to the degree of mixing of fluid (digesta) caused by peristalsis, although flow patterns in the gut are obviously much more complex. Fig. 4 shows the steady shear-flow profiles for solutions of a high MW $\left(2 \times 10^{6} \mathrm{Da}\right)$ oat $\beta$-glucan at different concentrations ${ }^{(60)}$. At low $\beta$-glucan concentrations (approximately lower than the overlap concentration $c^{*}$ ), the solution viscosity does not change with respect to shear rate, a form of behaviour that is typical of a Newtonian fluid. At high concentrations, however, shear-thinning behaviour is observed, meaning that the viscosity decreases with an increasing shear rate. Because of the shear-rate dependence of viscosity, the solution viscosities of different samples have to be compared at the same shear rate, most usefully the value at 'zero' shear rate is preferred. In heterogeneous systems containing a polysaccharide gum and insoluble particulates, which are common in food suspensions or ingested food mixed with digestive fluids (i.e. digesta) in the gut, more complex rheological behaviour is seen. For instance, if there is a high fractional volume of insoluble particulates present, the suspensions exhibit shear-thinning even at low shear rates (i.e. loss of the Newtonian plateau) and also substantial increases in viscosity are observed ${ }^{(61,62)}$. For calculation of the zero-shear viscosity from the flow profiles, see online supplementary material. As seen in the literature, most researchers, in an effort to simplify the

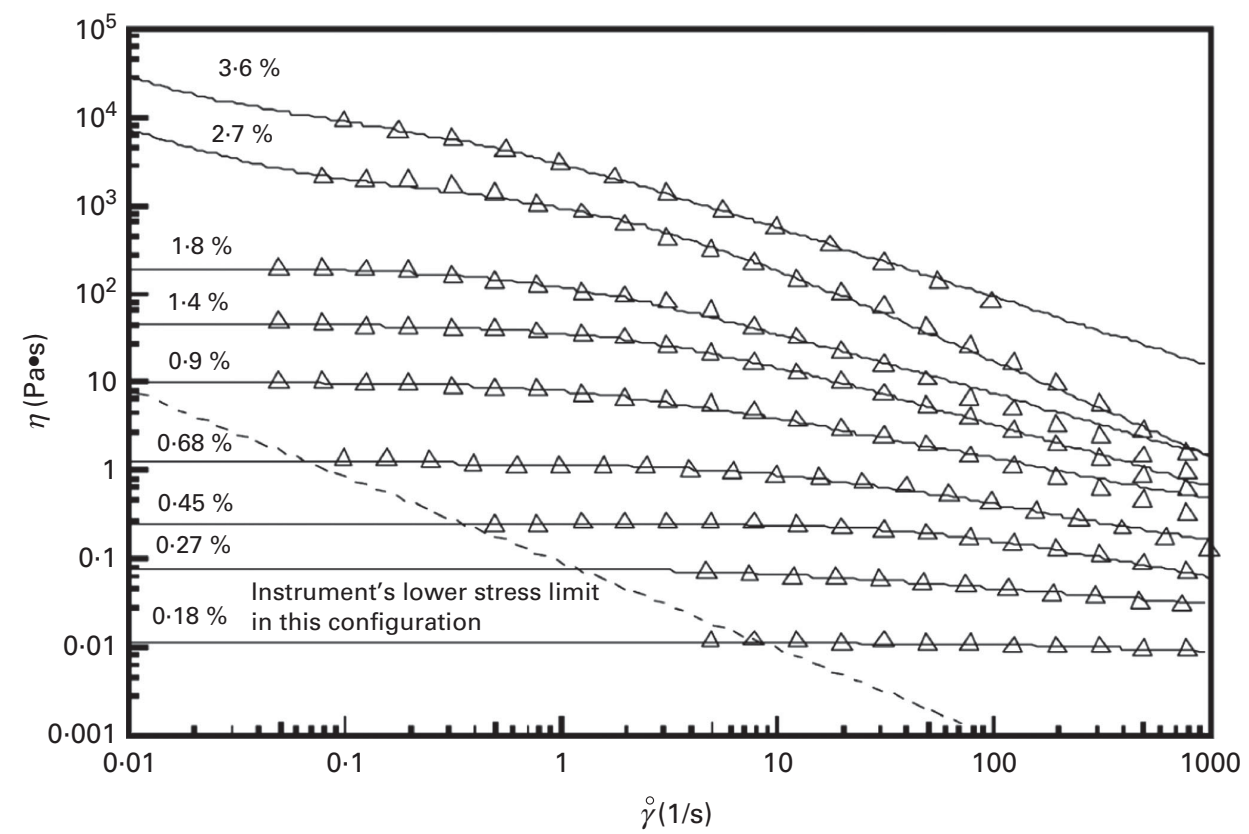

Fig. 4. Apparent viscosity $(\eta) v$. shear rate $(\dot{\gamma})$ for different concentrations of oat $\beta$-glucan solutions. (Re-printed, with permission, from Ren et al. $\left.{ }^{(60)}\right)$. 
method and obtain reproducible data, remove the particulate material by centrifugation before taking viscosity readings, because the presence of insoluble material can seriously interfere with measurements. Moreover, a single measurement of viscosity is often performed at an arbitrary shear rate (see Table 2). This is because the shear rates that occur in the intestinal lumen of human subjects and experimental animals following a meal containing a polysaccharide gum are not known and may vary at different regions of the gut and at different postprandial times. Also, zero shear viscosity is not always readily obtainable due to instrumental limitations. Caution is therefore needed when comparing viscosity data from different laboratories.

Solution viscosity is affected by the polymer concentration (c) and MW in a power-law relationship: $\eta \sim(c[\eta])^{n}$. The intrinsic viscosity, $[\eta]$, is a measure of hydrodynamic volume of the individual molecule in solution and is related to MW by, for instance, the Mark-Houwink relationship $\left([\eta]=k \quad \mathrm{MW}^{\alpha}\right.$, where $k$ and $\alpha$ are constants). Therefore, the parameter $c[\eta]$ represents the space occupancy of the polymer molecules in the solution by taking into account both concentration and MW factors. Fig. 5 is a double logarithmic plot of $\eta_{\mathrm{sp}, 0}$ (the specific viscosity at zero shear rate) $v$. the parameter $c \eta$ for oat $\beta$-glucan solutions. This plot consists of two linear regions connected by a continuous transition region starting at $\mathrm{c}[\eta]$ approximately 1 . The concentration at this point is designated $c^{*}$, which corresponds to the concentration at which individual $\beta$-glucan molecules begin to overlap. For example, for two $\beta$-glucans of MW 1 million Da and $0 \cdot 1$ million $\mathrm{Da}$, the $c^{*}$ values are approximately $0 \cdot 1$ and $0.5 \%$, respectively. At $c<c^{*}$, the solution is classified as being in a dilute regime and the relationship $\eta_{\mathrm{sp}, 0} \sim c^{1 \cdot 1}$ holds; whereas at $c>c^{*}$, the solution is classified as being in a semi-dilute regime and $\eta_{\mathrm{sp}, 0} \sim c^{44}$. It is well known that the viscosity of $\beta$-glucan solution changes more markedly with concentration in the semi-dilute solution than it does in dilute solution. The zero-shear viscosity at the critical concentration is approximately $1 \mathrm{mPa} \cdot \mathrm{s}$ (Fig. 5). In most clinical trials that showed positive blood-glucose and cholesterol-lowering effects, the viscosity (as estimated in vitro in the shear rate range $10-30 \mathrm{~s}^{-1}$ ) is considerably higher than this value (Table 2), although the in vivo viscosity may be different from that measured in vitro ${ }^{(63)}$. According to $\mathrm{Wood}^{(41)}$, the (in vitro viscosity) dose-response for the glycaemic response of $\beta$-glucan is in the range of $20-2000 \mathrm{mPa} \cdot \mathrm{s}$ (at shear rate $30 \mathrm{~s}^{-1}$ ). When the viscosity is lower than $20 \mathrm{mPa} \cdot \mathrm{s}$, no glucoselowering effect is observed, whereas when the viscosity is higher than $2000 \mathrm{mPa} \cdot \mathrm{s}$, no further reductions in blood glucose are seen. In other words, the metabolic response appears to reach a plateau above $2000 \mathrm{mPa} \cdot \mathrm{s}$. This highlights the importance that changes in MW have on the viscosity of $\beta$-glucan products, which in turn determines their physiological activity.

It must be emphasised that in vitro viscosities of polysaccharides might not accurately reflect the viscosities of these polymers when present in the GIT. The level of viscosity required to achieve a specific physiological effect has not been carefully reviewed and systematically studied. There are no data available on the direct measurements of luminal viscosity of oatmeals. However, studies by Marciani et $a l^{(64,65)}$ on locust bean gum, a source of water-soluble galactomannan with rheological properties similar to high MW oat $\beta$-glucan, provides some useful comparative information. In these studies, the gastric-content samples were obtained after ingestion of meals containing different doses of locust bean gum using nasogastric intubation and aspiration, and the viscosity was measured in vitro by a viscometer. This group also used an echo-planar MRI technique to measure the in vivo gastric lumen viscosity, which allowed viscosity to be measured non-invasively ${ }^{(64)}$. A good correlation was obtained between the rheological data from in vitro viscometry and echo-planar MRI. Table 2 lists the viscosity of test meals that have demonstrated positive physiological functions. Taking these data into consideration, along with the recommended minimum dose of oat $\beta$-glucan used for achieving significant physiological effects, the viscosity of the luminal digesta seems to fall within the lower end range of a semi-dilute regime (see Fig. 5).

From the analysis of data from Lan-Pidhainy et $a l^{(56)}$, it was found that the viscosity was related to concentration exponentially by an exponent of 1.51 , although the soluble $\beta$-glucan concentration was well within the range of the dilute regime. This is due, at least in part, to the existence of particulate materials, which are known to raise the viscosity of a solution/suspension as explained by Rayment et $a l{ }^{(61)}$. It is well documented that cereal $\beta$-glucan tends to form macromolecular aggregates in aqueous solutions ${ }^{(20,21,66)}$. Moreover, the low-MW oat $\beta$-glucan aggregates more easily than their high-MW counterparts ${ }^{(8,14,15)}$. Low-MW $\beta$-glucan solutions have been shown to have a 'yield stress flow' behaviour at very low shear rates giving higher than expected apparent viscosity values, which is attributed to the presence of $\beta$-glucan aggregates (Fig. 4) ${ }^{(2,60)}$.

\section{Impact on the blood-glucose and cholesterol-lowering properties}

The mechanisms by which oat $\beta$-glucan and other soluble fibres elicit their physiological effects on carbohydrate and lipid metabolism are discussed in the article on oats and CVD risk markers by Thies et al. ${ }^{(67)}$ in this Supplement. Although several mechanisms have been proposed, the ability of the soluble polysaccharide to increase the viscosity of the gut digesta, and thus to delay nutrient absorption from the gut, is believed to be a key factor ${ }^{(3,68)}$. Wood et al. ${ }^{(63)}$ first demonstrated an inverse linear relationship between peak postprandial blood glucose and insulin increments and $\log$ (viscosity) in healthy subjects who consumed glucose drinks containing extracted and purified $\beta$-glucan samples of different doses and MW values. A number of studies also reported that high-viscosity $\beta$-glucan drinks significantly attenuated postprandial glycaemia, but low-viscosity $\beta$-glucan showed no such effect ${ }^{(59)}$. A similar relationship was reported when $\beta$-glucan was incorporated into a food matrix such as baked goods and breakfast cereals ${ }^{(69,70)}$. Recently, an inverse linear relationship between glycaemic responses and in vitro viscosity of extracted $\beta$-glucan, as measured under simulated physiological conditions, was clearly demonstrated in healthy subjects consuming bread ${ }^{(71)}$, muffins $^{(52,72)}$ and granolas ${ }^{(73)}$ containing oat or barley $\beta$-glucans. 
Table 2. Examples of viscosity $(\eta)$ measured at specific shear rates $(\dot{\gamma})$ and temperature (temp.) of oat-containing meals tested in human studies, which have demonstrated positive postprandial blood-glucose lowering (PGL) and cholesterol-lowering $(C L)$ effects

\begin{tabular}{|c|c|c|c|c|c|c|}
\hline Type of food & Extraction method & $\begin{array}{l}\beta \text {-Glucan } \\
\text { dose }(\mathrm{g})\end{array}$ & $\begin{array}{c}\beta \text {-Glucan } \\
M_{\mathrm{p}} \text { or } M_{\mathrm{w}}{ }^{*}\left(\times 10^{-6} \mathrm{Da}\right) \\
\end{array}$ & $\begin{array}{c}\eta \text { (at } \dot{\gamma} \text {, and temp.) } \\
\text { (mPa.s) }\end{array}$ & $\begin{array}{l}\text { Metabolic } \\
\text { effects shown }\end{array}$ & Reference \\
\hline $\begin{array}{l}\text { Glucose drink with } \\
\beta \text {-glucan extract }\end{array}$ & Drink before consumption & $\begin{array}{l}1 \cdot 8 \\
3 \cdot 6 \\
7 \cdot 2\end{array}$ & ND & $\begin{array}{r}23\left(30 \mathrm{~s}^{-1}, 25^{\circ} \mathrm{C}\right) \\
159\left(30 \mathrm{~s}^{-1}, 25^{\circ} \mathrm{C}\right) \\
1940\left(30 \mathrm{~s}^{-1}, 25^{\circ} \mathrm{C}\right)\end{array}$ & PGL & Wood et al. ${ }^{(63)}$ \\
\hline Oat bran muffin & $\begin{array}{l}\text { Physiological extraction at } \\
37^{\circ} \mathrm{C}^{(30)}\end{array}$ & $\begin{array}{r}8 \\
12\end{array}$ & $\begin{array}{l}1 \cdot 8-2 \cdot 8 \\
2 \cdot 0-2 \cdot 7\end{array}$ & $\begin{array}{l}15 \cdot 2\left(30 \mathrm{~s}^{-1}, 37^{\circ} \mathrm{C}\right) \\
17 \cdot 8\left(30 \mathrm{~s}^{-1}, 37^{\circ} \mathrm{C}\right)\end{array}$ & PGL & $\begin{array}{l}\text { Lan-Pidhainy } \\
\text { et al. }{ }^{(56)}\end{array}$ \\
\hline Oat bran muffin & $\begin{array}{l}\text { Physiological extraction at } \\
37^{\circ} \mathrm{C}^{(30)}\end{array}$ & $\begin{array}{l}4 \\
8\end{array}$ & $\begin{array}{l}2 \cdot 2 \\
2 \cdot 2\end{array}$ & $\begin{array}{r}5.9\left(30 \mathrm{~s}^{-1}, 37^{\circ} \mathrm{C}\right) \\
29 \cdot 8\left(30 \mathrm{~s}^{-1}, 37^{\circ} \mathrm{C}\right)\end{array}$ & PGL & Tosh et al. ${ }^{(52)}$ \\
\hline $\begin{array}{l}\text { Glucose drink with } \\
\beta \text {-glucan concentrate }\end{array}$ & $\begin{array}{l}2 \mathrm{~h} \text { hydration of the drink } \\
\mathrm{mix} \text { at } 37^{\circ} \mathrm{C}\end{array}$ & 6 & ND & $3200\left(12.9 \mathrm{~s}^{-1}, 37^{\circ} \mathrm{C}\right)$ & PGL & $\begin{array}{l}\text { Panahi } \\
\text { et al. } .^{(59)}\end{array}$ \\
\hline Cereal with oat bran & $\begin{array}{l}\text { Physiological extraction at } \\
37^{\circ} \mathrm{C}^{(30)}\end{array}$ & $\begin{array}{l}3 \\
3 \\
4\end{array}$ & $\begin{array}{l}2 \cdot 2 \\
0.53 \\
0.85\end{array}$ & $\begin{array}{r}2930\left(30 \mathrm{~s}^{-1}, 37^{\circ} \mathrm{C}\right) \\
800\left(30 \mathrm{~s}^{-1}, 37^{\circ} \mathrm{C}\right) \\
1670\left(30 \mathrm{~s}^{-1}, 37^{\circ} \mathrm{C}\right)\end{array}$ & $\mathrm{CL}$ & $\begin{array}{l}\text { Wolever } \\
\text { et al. }{ }^{(81)}\end{array}$ \\
\hline Cereal with oat bran & $\begin{array}{l}\text { Physiological extraction at } \\
37^{\circ} \mathrm{C}^{(30)}\end{array}$ & $\begin{array}{l}8 \\
8 \\
8\end{array}$ & $\begin{array}{l}2 \cdot 2^{\star} \\
0.92^{\star} \\
0.63^{\star}\end{array}$ & $\begin{array}{r}2930\left(30 \mathrm{~s}^{-1}, 37^{\circ} \mathrm{C}\right) \\
1700\left(30 \mathrm{~s}^{-1}, 37^{\circ} \mathrm{C}\right) \\
800\left(30 \mathrm{~s}^{-1}, 37^{\circ} \mathrm{C}\right)\end{array}$ & PGL & $\begin{array}{l}\text { Brummer } \\
\text { et al. }{ }^{(69)}\end{array}$ \\
\hline $\begin{array}{l}\text { Granola bar with } \\
\text { oat bran and } \\
\text { rolled oats }\end{array}$ & $\begin{array}{l}\text { Physiological extraction at } \\
37^{\circ} \mathrm{C}^{(30)}\end{array}$ & $\begin{array}{l}6 \cdot 2 \\
6 \cdot 2\end{array}$ & $\begin{array}{l}2 \cdot 1 \\
0.43\end{array}$ & $\begin{array}{r}796\left(30 \mathrm{~s}^{-1}, 37^{\circ} \mathrm{C}\right) \\
66\left(30 \mathrm{~s}^{-1}, 37^{\circ} \mathrm{C}\right)\end{array}$ & PGL & $\begin{array}{l}\text { Regand } \\
\text { et al. }{ }^{73)}\end{array}$ \\
\hline
\end{tabular}

$M_{\mathrm{p}}$, peak molecular weight; $M_{\mathrm{w}}$, weight average molecular weight; values with *indicate $\mathrm{M}_{\mathrm{w}}$ only; ND, not determined.

In a recent human intervention trial using extruded breakfast cereal containing oat $\beta$-glucan of various MW values, Wolever et $a l^{\left({ }^{(7)}\right.}$ demonstrated an inverse relationship between serum LDL-cholesterol and $\log$ (viscosity), as measured by in vitro extraction under physiological conditions. These studies provide convincing evidence that the ability of $\beta$-glucan and other viscous polysaccharides to increase the digesta viscosity in the GIT is a key factor in determining their blood-glucose and cholesterol-lowering effects. In addition to this rheological mechanism, direct interference of soluble fibre with the biochemical degradation of starch $^{(73,75,76)}$ and bile-acid binding ${ }^{(5)}$ have been reported to contribute to these beneficial effects on metabolism.

Although numerous human trials have been carried out to test oat $\beta$-glucans from various sources and present in different forms of foods, only some of these studies showed reductions in blood-cholesterol and -glucose concentrations $^{(77-79)}$. This discrepancy can be attributed to a range of factors, apart from the $\beta$-glucan dosage used, that may potentially affect the amount and MW of solubilised $\beta$-glucan in the GIT by influencing the alimentary viscosity. Regand et al. ${ }^{(72)}$ reported that depolymerisation of $\beta$-glucan in bread and pasta reduced its efficacy in attenuating the peak blood-glucose response in healthy human subjects. The same group also found that an extruded oat-based breakfast cereal given at a dose of $3 \mathrm{~g}$ of oat $\beta$-glucan/d with a high $\left(2.2 \times 10^{6} \mathrm{Da}\right)$ or medium $\left(0.5 \times 10^{6} \mathrm{Da}\right)$ MW lowered LDL-cholesterol similarly ( $5 \%$ ), but the efficacy was reduced by $50 \%$ when MW was reduced to $0.2 \times 10^{6} \mathrm{Da}^{(74)}$. Kerckhoffs et $a l .{ }^{(31)}$ also demonstrated that the cholesterol-lowering effect of $\beta$-glucan from oat bran administered in orange juice diminished when the same $\beta$-glucan is incorporated into bread and cookies. Depolymerisation of $\beta$-glucan and/or reduced solubility in food may account for the attenuation in efficacy reported for the latter products. Moreover, it has been shown that the reduced solubility induced by freezethaw cycling ${ }^{(56)}$ or gelation ${ }^{(80)}$ decreased the efficacy of $\beta$-glucan in lowering postprandial glycaemic responses in human subjects. These studies provide compelling evidence that the physico-chemical properties of oat $\beta$-glucan play a crucial role in determining its physiological functions. Thus, reduced solubility and/or MW of $\beta$-glucan might be responsible for some of the published studies that failed to show positive metabolic effects of oat products.

\section{Conclusions and future research}

Based on the results of physiological and human studies to date, there is strong evidence to show that oat $\beta$-glucan lowers total and LDL-cholesterol and attenuates postprandial glycaemia and insulinaemia when it is ingested in sufficiently high doses and at a suitably high MW. The physico-chemical properties of oat $\beta$-glucan, namely MW and solubility, should be considered when assessing the physiological properties. Oat $\beta$-glucan concentrates or isolates have shown similar beneficial effects to oat bran and rolled oats, provided that detrimental processing conditions are avoided.

The current recommended intake of $\geq 3 \mathrm{~g} / \mathrm{d} \beta$-glucan by US Food and Drug Administration does not ensure a significant decrease in blood cholesterol, because the quantity of 


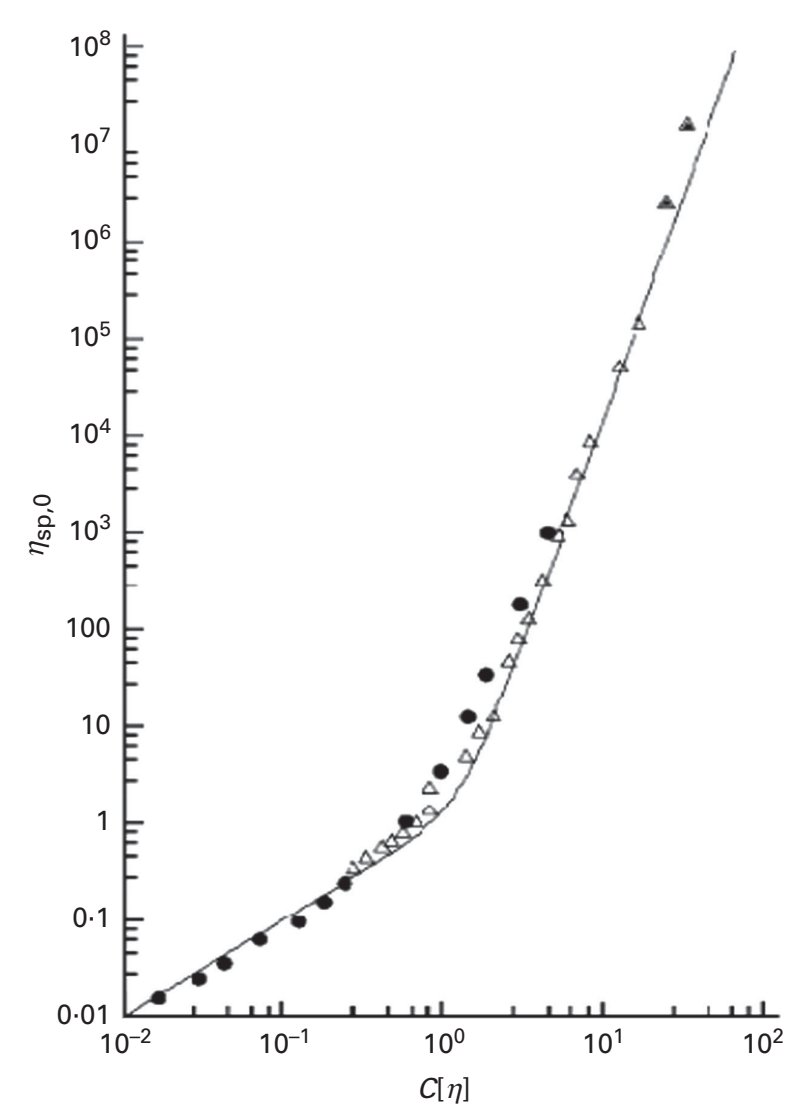

Fig. 5. $\log \eta_{\mathrm{sp}, 0}$ (the specific viscosity at zero shear rate) $v . \log c[\eta]$ for oat $\beta$-glucan. $\bullet$ : data of Doublier \& $\operatorname{Wood}^{(2)} ; \Delta$ : data from Ren et al. ${ }^{(60)}$ (Reprinted, with permission, from Ren et al. ${ }^{(60)}$ ).

$\beta$-glucan ingested does not solely determine the physiological efficacy. It is the amount and MW of $\beta$-glucan that become solubilised in the GIT that determines, to a large extent, the blood-glucose and cholesterol-lowering properties. Clear inverse linear relationships have been demonstrated between the in vitro log (viscosity) of drink or extracts from solid foods and postprandial blood-glucose or fasting bloodcholesterol concentrations. It appears that there is a range of viscosity values over which $\beta$-glucan exhibits such biological activities, although the minimum and maximum values for this range need to be defined. There is little doubt that in vitro evaluation can be effectively used to screen oat products in order to increase the likelihood of success in achieving beneficial biological effects in human subjects. How the viscosity of drinks or extracts measured in vitro corresponds to the in vivo viscosity developed in the GIT is not straightforward. A combination of factors, including the dilution effects of digestive fluids, enzymic degradation of $\beta$-glucan and interaction of this polymer with other food components, is likely to influence the in vivo viscosity. Direct measurements of viscosity in the human gut have not yet been carried out on ingested oat products, as has been done with other polysaccharides such as the leguminous galactomannans (locust bean gum) ${ }^{(64,65)}$. Accordingly, the minimum in vivo viscosity that is required to achieve desirable metabolic effects is currently unknown.
The development of inexpensive and palatable oat-containing products, which are still physiologically effective, is needed in the future. To facilitate this, it is necessary to establish a standardised protocol to characterise $\beta$-glucan products, which provides sufficient physico-chemical data to allow useful comparisons and interpretations to be made of the results obtained in various human studies.

\section{Supplementary material}

To view supplementary material for this article, please visit http://dx.doi.org/10.1017/S0007114514002256

\section{Acknowledgements}

The authors thank Shea Miller at Agriculture and Agri-Food Canada (AAFC) for providing Fig. 2 and Peter Butterworth (Kings College London), Simon Ross-Murphy (University of Nottingham), and Steve Cui and Susan Tosh of AAFC for helpful feedback on various drafts of the present paper. The authors dedicate this review to the late Peter Wood, a close colleague and friend of both the authors, for his huge research contribution to the structure, properties and nutritional effects of oat $\beta$-glucan. Q. W. received an honorarium from Quaker Oats Company (a subsidiary of PepsiCo, Inc.) for attending the workshop in May 2012 to discuss the content of the supplement. Research in the laboratory of P. R. E. was funded by the Biotechnology and Biological Sciences Research Council, UK.

Author contributions: Q. W. drafted the paper and P. R. E. contributed to writing and editing the paper.

This paper was published as part of a supplement to British Journal of Nutrition, publication of which was supported by an unrestricted educational grant from Quaker Oats Co. (a subsidiary of PepsiCo Inc.). The papers included in this supplement were invited by the Guest Editor and have undergone the standard journal formal review process. They may be cited.

The Guest Editor to this supplement is Roger Clemens. The Guest Editor declares no conflict of interest.

\section{References}

1. Parrish FW, Perlin AS \& Reese ET (1960) Selective enzymolysis of poly- $\beta$-D-glucans, and the structure of the polymers. Can J Chem 38, 2094-2104.

2. Doublier JL \& Wood PJ (1995) Rheological properties of aqueous solutions of $(1,3)(1,4)-\beta$-D-glucan from oats (Avena sativa L.). Cereal Chem 72, 335-340.

3. Judd PA \& Ellis PR (2006) Plant polysaccharides in the prevention and treatment of diabetes mellitus. In Traditional Medicines for Modern Times, Antidiabetic Plants, pp. 257-272 [A Soumyanath, editor]. Boca Raton, FL: CRC Press (Taylor \& Francis Group).

4. Andersson M, Ellegård L \& Andersson H (2002) Oat bran stimulates bile acid synthesis within $8 \mathrm{~h}$ as measured by $7 \alpha$-hydroxy4-cholesten-3-one. Am J Clin Nutr 76, 1111-1116.

5. Kim HJ \& White PJ (2012) Interactional effects of $\beta$-glucan, starch, and protein in heated oat slurries on viscosity and in vitro bile acid binding. J Agr Food Chem 60, 6217-6222.

6. Lia A., Hallmans G, Sandberg AS, et al. (1995) Oat $\beta$-glucan increases bile acid excretion and a fiber-rich barley fraction 
increases cholesterol excretion in ileostomy subjects. $A m \mathrm{~J}$ Clin Nutr 62, 1245-1251.

7. Kim HJ \& White PJ (2013) Impact of the molecular weight, viscosity, and solubility of $\beta$-glucan on in vitro oat starch digestibility. J Agr Food Chem 61, 3270-3277.

8. Cui W, Wood PJ, Blackwell B, et al. (2000) Physicochemical properties and structural characterization by two-dimensional NMR spectroscopy of wheat $\beta$-D-glucan-comparison with other cereal $\beta$-D-glucans. Carbohydr Polym 41, 249-258.

9. Cui SW \& Wood PJ (2000) Relationships between structural features, molecular weight and rheological properties of cereal $\beta$-D-glucans. In Hydrocolloids: Physical Chemistry and Industrial Application of Gels, Polysaccharides and Proteins, pp. 159-168 [K Nishinari, editor]. London: Elsevier.

10. Miller SS, Wood PJ, Pietrzak LN, et al. (1993) Mixed linkage $\beta$-glucan, protein content, and kernel weight in Avena species. Cereal Chem 70, 231-233.

11. Autio K, Myllymäki O, Suortti T, et al. (1992) Physical properties of $(1 \rightarrow 3)(1 \rightarrow 4)-\beta$-D-glucan preparates isolated from Finnish oat varieties. Food Hydrocolloid 5, 513-522.

12. Vårum KM \& Smidsrød O (1988) Partial chemical and physical characterisation of $(1 \rightarrow 3)(1 \rightarrow 4)-\beta$-D-glucans from oat (Avena sativa L.) aleurone. Carbohydr Polym 9, 103-117.

13. Ghotra BS, Vasanthan T, Wettasinghe M, et al. (2007) ${ }^{31} \mathrm{P}$-nuclear magnetic resonance spectroscopic analysis of phosphorus in oat and barley $\beta$-glucans. Food Hydrocolloid 21, 1056-1061.

14. Lazaridou A \& Biliaderis CG (2004) Cryogelation of cereal $\beta$-glucans: structure and molecular size effects. Food Hydrocolloid 18, 933-947.

15. Lazaridou A, Biliaderis CG \& Izydorczyk MS (2003) Molecular size effects on rheological properties of oat $\beta$-glucans in solution and gels. Food Hydrocolloid 17, 693-712.

16. Vårum KM, Martinsen A \& Smidsrød O (1991) Fractionation and viscometric characterization of a $(1 \rightarrow 3)(1 \rightarrow 4)$ $\beta$-D-glucan from oat, and universal calibration of a high-performance size-exclusion chromatographic system by the use of fractionated $\beta$-glucans, alginates and pullulans. Food Hydrocolloid 5, 363-374.

17. Wang Q, Wood PJ \& Cui W (2002) Microwave assisted dissolution of $\beta$-glucan in water - implications for the characterisation of this polymer. Carbohydr Polym 47, 35-38.

18. Roubroeks JP, Mastromauro DI, Andersson R, et al. (2000) Molecular weight, structure, and shape of oat $(1 \rightarrow 3)$ $(1 \rightarrow 4)$ - $\beta$-D-glucan fractions obtained by enzymatic degradation with lichenase. Biomacromolecules 1, 584-591.

19. Vårum KM, Smidsrod O \& Brant DA (1992) Light scattering reveals micelle-like aggregation in the (1-3)(1-4)- $\beta$-D-glucans from oat aleurone. Food Hydrocolloid 5, 497-511.

20. Li W, Wang Q, Cui SW, et al. (2006) Elimination of aggregates of $(1 \rightarrow 3)(1 \rightarrow 4)-\beta$-D-glucan in dilute solutions for light scattering and size exclusion chromatography study. Food Hydrocolloid 20, 361-368.

21. Wang Q, Wood PJ, Cui W, et al. (2001) The effect of autoclaving on the dispersibility and stability of three neutral polysaccharides in dilute aqueous solutions. Carbobydr Polym 45, 355-362.

22. Wood PJ (1991) Oat $\beta$-glucan-physicochemical properties and physiological effects. Trends Food Sci Technol 2, 311-314.

23. Rimsten L, Stenberg T, Andersson R, et al. (2003) Determination of $\beta$-glucan molecular weight using SEC with calcofluor detection in cereal extracts. Cereal Chem 80, 485-490.

24. Andersson AAM \& Börjesdotter D (2011) Effects of environment and variety on content and molecular weight of $\beta$-glucan in oats. J Cereal Sci 54, 122-128.
25. Ajithkumar A, Andersson R \& Åman P (2005) Content and molecular weight of extractable $\beta$-glucan in American and Swedish oat samples. J Agr Food Chem 53, 1205-1209.

26. Wood PJ, Siddiqui IR \& Paton D (1978) Extraction of high viscosity gums from oats. Cereal Chem 55, 1038-1049.

27. Wood PJ (1986) Oat $\beta$-glucan: structure, location, and properties. In Oats: Chemistry and Technology, 1st ed., pp. 121-152 [FH Webster, editor]. St Paul, MN: American Association of Cereal Chemists.

28. Doehlert DC, Zhang D \& Moore WR (1997) Influence of heat pretreatments of oat grain on the viscosity of flour slurries. J Sci Food Agr 74, 125-131.

29. Andersson AAM, Armö E, Grangeon E, et al. (2004) Molecular weight and structure units of $(1 \rightarrow 3)(1 \rightarrow 4)$ - $\beta$-glucans in dough and bread made from hull-less barley milling fractions. J Cereal Sci 40, 195-204.

30. Beer MU, Wood PJ, Weisz J, et al. (1997) Effect of cooking and storage on the amount and molecular weight of $(1 \rightarrow 3)(1 \rightarrow 4)-\beta$-D-glucan extracted from oat products by an in vitro digestion system. Cereal Chem 74, 705-709.

31. Kerckhoffs DAJM, Hornstra G \& Mensink RP (2003) Cholesterol-lowering effect of $\beta$-glucan from oat bran in mildly hypercholesterolemic subjects may decrease when $\beta$-glucan is incorporated into bread and cookies. Am J Clin Nutr 78, 221-227.

32. Tosh SM, Brummer Y, Miller SS, et al. (2010) Processing affects the physicochemical properties of $\beta$-glucan in oat bran cereal. J Agr Food Chem 58, 7723-7730.

33. Åman P, Rimsten L \& Andersson R (2004) Molecular weight distribution of $\beta$-glucan in oat-based foods. Cereal Chem 81, 356-360.

34. Decker EA, Rose D \& Stewart D (2014) Processing of oats and the impact of processing operations on nutrition and health benefits. Br J Nutr 112, S58-S64.

35. Peterson DM, Wesenberg DM \& Burrup DE (1995) $\beta$-Glucan content and its relationship to agronomic characteristics in elite oat germplasm. Crop Sci 35, 965-970.

36. Saastamoinen M, Hietaniemi V, Pihlava JM, et al. (2004) $\beta$-Glucan contents of groats of different oat cultivars in official variety, in organic cultivation, and in nitrogen fertilization trials in Finland. Agr Food Sci 13, 68-79.

37. Dvončová D, Havrlentová M, Hlinková A, et al. (2010) Effect of fertilization and variety on the $\beta$-glucan content in the grain of oats. Food Sci Tech Quality 17, 108-116.

38. Miller SS \& Fulcher RG (2011) Microstructure and chemistry of the oat kernel. In Oats: Chemistry and Technology, 2nd ed., pp. 77-94 [FH Webster and PJ Wood, editors]. St Paul, MN: AACC.

39. Wood PJ \& Fulcher RG (1978) Interaction of some dyes with cereal $\beta$-glucans. Cereal Chem 55, 952-966.

40. Johansson L, Tuomainen P, Anttila H, et al. (2007) Effect of processing on the extractability of oat $\beta$-glucan. Food Chem 105, 1439-1445.

41. Wood PJ (2011) Oat $\beta$-glucan: properties and function. In Oats: Chemistry and Technology, 2nd ed., pp. 219-254. St Paul, MN: AACC.

42. Stevenson DG (2011) Oat dietary fiber: commercial processes and functional attributes. In Oats: Chemistry and Technology, 2nd ed., pp. 321-332 [FH Webster and PJ Wood, editors]. St Paul, MN: AACC.

43. Lebet V, Arrigoni E \& Amado R (1998) Digestion procedure using mammalian enzymes to obtain substrates for in vitro fermentation studies. Lebensm-Wiss Technol 31, 509-515.

44. Jørgensen KG \& Aastrup S (1988) Quantification of high molecular weight $(1 \rightarrow 3)(1 \rightarrow 4)-\beta$-D-glucan using Calcofluor complex formation and flow injection analysis. II. 
Determination of total $\beta$-glucan content of barley and malt. Carlsberg Res Commun 53, 287-296.

45. McCleary BV \& Glennie-Holmes M (1985) Enzymatic quantification of $(1 \rightarrow 3)(1 \rightarrow 4)-\beta$-D-glucan in barley and malt. J Inst Brewing 91, 285-295.

46. Gamel TH, Abdel-Aal ESM, Wood PJ, et al. (2012) Application of the rapid Visco Analyzer (RVA) as an effective rheological tool for measurement of $\beta$-glucan viscosity. Cereal Chem 89, 52-58.

47. Asp NG, Johansson CG, Hallmer H, et al. (1983) Rapid enzymatic assay of insoluble and soluble dietary fiber. J Agr Food Chem 31, 476-482.

48. Mälkki Y, Autio K, Hanninen O, et al. (1992) Oat bran concentrates: physical properties of $\beta$-glucan and hypocholesterolemic effects in rats. Cereal Chem 69, 647-653.

49. Zhang M, Bai X \& Zhang Z (2011) Extrusion process improves the functionality of soluble dietary fiber in oat bran. J Cereal Sci 54, 98-103.

50. Degutyte-Fomins L, Sontag-Strohm T \& Salovaara H (2002) Oat bran fermentation by rye sourdough. Cereal Chem 79, 345-348.

51. Zhang D, Doehlert DC \& Moore WR (1998) Rheological properties of $(1 \rightarrow 3),(1 \rightarrow 4)-\beta$-D-glucans from raw, roasted, and steamed oat groats. Cereal Chem 75, 433-438.

52. Tosh SM, Brummer Y, Wolever TMS, et al. (2008) Glycemic response to oat bran muffins treated to vary molecular weight of $\beta$-glucan. Cereal Chem 85, 211-217.

53. Wang Q, Ellis PR \& Ross-Murphy SB (2003) Dissolution kinetics of guar gum powders - II. Effects of concentration and molecular weight. Carbohydr Polym 53, 75-83.

54. Wong BT, Day L \& Augustin MA (2011) Deamidated wheat protein-dextran Maillard conjugates: effect of size and location of polysaccharide conjugated on steric stabilization of emulsions at acidic pH. Food Hydrocolloid 25, 1424-1432.

55. Tosh SM, Wood PJ, Wang Q, et al. (2004) Structural characteristics and rheological properties of partially hydrolyzed oat $\beta$-glucan: the effects of molecular weight and hydrolysis method. Carbohydr Polym 55, 425-436.

56. Lan-Pidhainy X, Brummer Y, Tosh SM, et al. (2007) Reducing $\beta$-glucan solubility in oat bran muffins by freeze-thaw treatment attenuates its hypoglycemic effect. Cereal Chem 84, 512-517.

57. Wang Q, Ellis PR \& Ross-Murphy SB (2008) Dissolution kinetics of water-soluble polymers: the guar gum paradigm. Carbohydr Polym 74, 519-526.

58. Wang Q, Ellis PR \& Ross-Murphy SB (2006) Dissolution kinetics of guar gum powders - III. Effect of particle size. Carbohydr Polym 64, 239-246.

59. Panahi S, Ezatagha A, Temelli F, et al. (2007) $\beta$-Glucan from two sources of oat concentrates affect postprandial glycemia in relation to the level of viscosity. J Am Coll Nutr 26, 639-644.

60. Ren Y, Ellis PR, Ross-Murphy SB, et al. (2003) Dilute and semi-dilute solution properties of $(1 \rightarrow 3)(1 \rightarrow 4)-\beta$-Dglucan, the endosperm cell wall polysaccharide of oats (Avena sativa L.). Carbohydr Polym 53, 401-408.

61. Rayment P, Ross-Murphy SB \& Ellis PR (2000) Effect of size and shape of particulate inclusions on the rheology of guar galactomannan solutions. Carbohydr Polym 43, 1-9.

62. Rayment P, Ross-Murphy SB \& Ellis PR (1995) Rheological properties of guar galactomannan and rice starch mixtures - I. Steady shear measurements. Carbohydr Polym 28, 121-130.

63. Wood PJ, Braaten JT, Scott FW, et al. (1994) Effect of dose and modification of viscous properties of oat gum on plasma glucose and insulin following an oral glucose load. Br J Nutr 72, 731-743.
64. Marciani L, Manoj P, Hills BP, et al. (1998) Echo-planar imaging relaxometry to measure the viscosity of a model meal. J Magn Reson 135, 82-86.

65. Marciani L, Gowland PA, Spiller RC, et al. (2000) Gastric response to increased meal viscosity assessed by echoplanar magnetic resonance imaging in humans. J Nutr $\mathbf{1 3 0}$, $122-127$.

66. Tosh SM, Wood PJ \& Wang Q (2003) Gelation characteristics of acid-hydrolyzed oat beta-glucan solutions solubilized at a range of temperatures. Food Hydrocolloid 17, 523-527.

67. Thies F, Masson LF, Boffetta P, et al. (2014) Oats and CVD risk markers: a systematic literature review. Br J Nutr $\mathbf{1 1 2}$ S19-S30

68. Jenkins DJA, Wolever TMS, Leeds AR, et al. (1978) Dietary fibres, fibre analogues, and glucose tolerance: importance of viscosity. Br Med J 1, 1392-1394.

69. Brummer Y, Duss R, Wolever TMS, et al. (2012) Glycemic response to extruded oat bran cereals processed to vary in molecular weight. Cereal Chem 89, 255-261.

70. Tappy L, Gügolz E \& Würsch P (1996) Effects of breakfast cereals containing various amounts of $\beta$-glucan fibers on plasma glucose and insulin responses in NIDDM subjects. Diabetes Care 19, 831-834.

71. Östman E, Rossi E, Larsson H, et al. (2006) Glucose and insulin responses in healthy men to barley bread with different levels of $(1 \rightarrow 3)(1 \rightarrow 4)$ - $\beta$-glucans; predictions using fluidity measurements of in vitro enzyme digests. J Cereal Sci $\mathbf{4 3}$, $230-235$.

72. Regand A, Tosh SM, Wolever TMS, et al. (2009) Physicochemical properties of glucan in differently processed oat foods influence glycemic response. J Agr Food Chem 57, $8831-8838$.

73. Regand A, Chowdhury Z, Tosh SM, et al. (2011) The molecular weight, solubility and viscosity of oat beta-glucan affect human glycemic response by modifying starch digestibility. Food Chem 129, 297-304.

74. Wolever TMS, Tosh SM, Gibbs AL, et al. (2010) Physicochemical properties of oat $\beta$-glucan influence its ability to reduce serum LDL cholesterol in humans: a randomized clinical trial. Am J Clin Nutr 92, 723-732.

75. Slaughter SL, Ellis PR, Jackson EC, et al. (2002) The effect of guar galactomannan and water availability during hydrothermal processing on the hydrolysis of starch catalysed by pancreatic $\alpha$-amylase. Biochim Biophys Acta 1571, 55-63.

76. Brennan CS, Blake DE, Ellis PR, et al. (1996) Effects of guar galactomannan on wheat bread microstructure and on the in vitro and in vivo digestibility of starch in bread. J Cereal Sci 24, 151-160.

77. Keogh GF, Cooper GJS, Mulvey TB, et al. (2003) Randomized controlled crossover study of the effect of a highly $\beta$-glucanenriched barley on cardiovascular disease risk factors in mildly hypercholesterolemic men. Am J Clin Nutr 78, 711-718.

78. Poppitt SD (2007) Soluble fibre oat and barley $\beta$-glucan enriched products: can we predict cholesterol-lowering effects? Br J Nutr 97, 1049-1050.

79. Tosh SM (2013) Review of human studies investigating the post-prandial blood-glucose lowering ability of oat and barley food products. Eur J Clin Nutr 67, 310-317.

80. Kwong MGY, Wolever TMS, Brummer Y, et al. (2013) Attenuation of glycemic responses by oat $\beta$-glucan solutions and viscoelastic gels is dependent on molecular weight distribution. Food Funct 4, 401-408.

81. Wolever TMS, Gibbs AL, Brand-Miller J, et al. (2011) Bioactive oat-glucan reduces LDL cholesterol in Caucasians and non-Caucasians. Nutr J 10, 130. 